\title{
Understanding Worker Well-Being Relative to High-Workload and Recovery Activities across a Whole Day: Pilot Testing an Ecological Momentary Assessment Technique
}

\author{
Raymond Hernandez ${ }^{1, *}$, Elizabeth A. Pyatak ${ }^{1}{ }^{\mathbb{D}}$, Cheryl L. P. Vigen ${ }^{1}$, Haomiao Jin ${ }^{2}$, Stefan Schneider ${ }^{2} \mathbb{D}$, \\ Donna Spruijt-Metz ${ }^{2,3,4}$ and Shawn C. Roll ${ }^{1}$ (D) \\ 1 Chan Division of Occupational Science and Occupational Therapy, University of Southern California, \\ Los Angeles, CA 90089, USA; beth.pyatak@usc.edu (E.A.P.); vigen@usc.edu (C.L.P.V.); sroll@usc.edu (S.C.R.) \\ 2 Dornsife Center for Economic \& Social Research, University of Southern California, \\ Los Angeles, CA 90089, USA; haomiaoj@usc.edu (H.J.); schneids@usc.edu (S.S.); dmetz@usc.edu (D.S.-M.) \\ 3 Keck School of Medicine, University of Southern California, Los Angeles, CA 90033, USA \\ 4 Department of Psychology, University of Southern California, Los Angeles, CA 90089, USA \\ * Correspondence: hray57024@gmail.com
}

check for updates

Citation: Hernandez, R.; Pyatak,

E.A.; Vigen, C.L.P.; Jin, H.; Schneider,

S.; Spruijt-Metz, D.; Roll, S.C.

Understanding Worker Well-Being

Relative to High-Workload and

Recovery Activities across a Whole

Day: Pilot Testing an Ecological

Momentary Assessment Technique.

Int. J. Environ. Res. Public Health 2021,

18, 10354. https://doi.org/10.3390/

ijerph181910354

Academic Editors: Sara L. Tamers, L. Casey Chosewood and Jessica Streit

Received: 24 August 2021

Accepted: 28 September 2021

Published: 1 October 2021

Publisher's Note: MDPI stays neutral with regard to jurisdictional claims in published maps and institutional affiliations.

Copyright: (c) 2021 by the authors. Licensee MDPI, Basel, Switzerland. This article is an open access article distributed under the terms and conditions of the Creative Commons Attribution (CC BY) license (https:// creativecommons.org/licenses/by/ $4.0 /)$.

\begin{abstract}
Occupational health and safety is experiencing a paradigm shift from focusing only on health at the workplace toward a holistic approach and worker well-being framework that considers both work and non-work factors. Aligned with this shift, the purpose of this pilot study was to examine how, within a person, frequencies of high-workload and recovery activities from both work and non-work periods were associated with same day well-being measures. We analyzed data on 45 workers with type 1 diabetes from whom we collected activity data 5-6 times daily over 14 days. More frequent engagement in high-workload activities was associated with lower well-being on multiple measures including higher stress. Conversely, greater recovery activity frequency was mostly associated with higher well-being indicated by lower stress and higher positive affect. Overall, our results provide preliminary validity evidence for measures of high-workload and recovery activity exposure covering both work and non-work periods that can inform and support evaluations of worker well-being.
\end{abstract}

Keywords: workload; recovery; ecological momentary assessment; type 1 diabetes; workweek; healthy work design and well-being; future of work

\section{Introduction}

The future of work is projected to bring with it several novel and complex concerns, prompting the National Institute for Occupational Safety and Health (NIOSH) to develop and promote holistic and transdisciplinary approaches to worker health and well-being [1]. Advances in technology are expected to continue influencing how workers engage in work and their workplace, including an increased frequency of remote work [2] and a greater degree of job automation [3]. The COVID-19 pandemic has drastically increased the pace at which remote working arrangements have been adopted, with roughly $35 \%$ of employees working from home at the height of the pandemic [4]. Anticipated consequences of these changes include blurring of work-life boundaries, greater expectation of work availability outside of standard hours, and increased potential for isolation [3,5]. To address these consequences, NIOSH implemented the Total Worker Health ${ }^{\circledR}$ (TWH) program, which aims to protect workers from work-related safety and health hazards while also promoting their health more generally [6]. NIOSH also proposed a new worker well-being framework that reflects this holistic paradigm shift and supports consideration of non-work factors that could impact worker health [7]. This expanded approach to worker well-being integrates work and non-work health promotion, acknowledging that both personal and occupational risk factors may contribute in an additive fashion to health and safety outcomes [8]. 
Workload and recovery are frequent areas of worker health research that could benefit from this more holistic and integrated perspective on supporting worker health and wellbeing. Workload is most commonly associated with working adults, who are exposed to higher amounts of workload from their paid employment $[9,10]$ than are other populations, such as retirees [11]. However, workload can be more broadly considered as the cost (e.g., fatigue, stress, illness) of performing any tasks [12], whereby high-workload activities can be experienced in both work and non-work times. For instance, caregiving is a potential source of non-work, high workload [13]. Recovery is the process that repairs the negative strain effects stemming from exposure to stressors [14], a concept that is often applied to leisure time or sleep but can also be found in activities throughout a workday. Although workload and recovery apply to both work and non-work activities that individuals engage in throughout a day, prior studies have typically partitioned the investigation of exposures by examining high workload at work [15] and recovery during non-work time [10]. As such, excessive exposure to high-workload tasks from work has frequently been associated with poorer psychological and physical well-being [15-17], while greater engagement in recovery after work has been associated with positive health and well-being outcomes [18].

Despite conceptual support using a siloed approach, the TWH philosophy and emerging holistic frameworks indicate that worker well-being may best be understood by examining activity engagement across both contexts to more fully capture the combined effects of workload and recovery [8]. That is, just as breaks taken during work are likely important to consider as part of total recovery, high-workload engagements during non-work time are also likely essential for measuring total workload.

We are, in essence, suggesting the need for an expanded scope within the EffortRecovery model that accounts for both work and non-work activity engagements. According to this model, which was in part based on exercise literature, exerting effort (i.e., exposure to workload) during work leads to load reactions, acute changes to psychobiological systems that are adaptive in the short term in that they help in meeting task demands [9]. Adequate time for recovery, defined as return of psychobiological systems to baseline after exertion ceases, allows for reversal of the load reactions and a return of psychobiological systems to pre-demand levels [9]. With sufficient recovery, fatigue and other manifestations of load reactions are reduced [19]. Insufficient recovery however can lead to impaired well-being [19]. Much work has been investigating the nuances of the relationships between effort/recovery and well-being. For instance, job autonomy, role clarity, and social support have been theorized as potential moderators of the link between workload and well-being [20]. Here, however, we focus on the assertion that while the Effort-Recovery model traditionally focuses on work contexts, consideration of both work and non-work activity engagements may be needed to capture full exposure to effort (i.e., workload) and recovery. This would create a fuller picture of how well-being emerges compared to a siloed approach, where part of the picture is missing.

The purpose of this pilot study was to examine the feasibility of ecological momentary assessment (EMA), i.e., repeated sampling of behaviors and experiences in real time and in natural environments [21], as a method for investigating worker health and well-being as part of this expanded scope. Specifically, we collected EMA data five to six times a day for 14 days to examine how the frequencies of workers' exposure to high-workload and recovery activities, across both work and non-work periods over whole days, were associated with same day well-being measures. As shown in Table 1, we expected that valid EMA data would result in the following: (1) frequency of high-workload activities across a whole day would be positively associated with end of day workload [9] and negatively associated with well-being [15], and (2) frequency of recovery activities across a whole day would be negatively associated with workload [9] and positively associated with well-being [22,23]. 
Table 1. Hypothesized intra-person correlations between relative activity frequency and measures of workload and well-being.

\begin{tabular}{|c|c|c|c|c|c|c|c|}
\hline & \multicolumn{3}{|c|}{ Workload } & \multicolumn{4}{|c|}{ Well-Being } \\
\hline & $\begin{array}{l}\text { Overall Task } \\
\text { Load }\end{array}$ & Work Hours & Stress & Fatigue & Pain & $\begin{array}{c}\text { Positive } \\
\text { Affect }\end{array}$ & $\begin{array}{c}\text { Negative } \\
\text { Affect }\end{array}$ \\
\hline High workload activity frequency & + & + & + & + & + & - & + \\
\hline Recovery activity frequency & - & - & - & - & - & + & - \\
\hline
\end{tabular}

-: negative correlation; +: positive correlation.

\section{Materials and Methods}

\subsection{Study Overview}

We analyzed data collected as part of a multisite study investigating the relationship between function, emotion, and blood glucose in adults with type 1 diabetes (T1D), described in greater detail in the published study methodology paper [24]. Participants aged 18-75 with T1D were recruited from three clinical sites, two in Los Angeles and one in New York, through mailings, phone calls, email invitations, and health provider referrals. Due to similarities in the implications of having chronic conditions, we anticipated that our T1D population may be somewhat similar to other worker populations with chronic conditions, thereby increasing the potential generalizability of our results (discussed further in Section 4.3). Only participants that identified as workers were included in analyses. Participants completed a baseline survey battery, 14 days of EMA data collection with 5-6 surveys per day, and a follow-up survey battery. The data collection procedures were approved by the University of Southern California Institutional Review Board. Subjects provided informed consent to participate in the study electronically through the REDCap e-consent framework [25].

\subsection{Measures}

For approximately two weeks, EMA surveys were administered on smartphones with up to 6 momentary surveys per day at 3-h intervals, using the Mobile EMA application (mEMA: ilumivu.com). Relative to other data collection methods such as end of day surveys or time diaries, an advantage of EMA is reduced recall bias since data are reported immediately after experiences of interest have occurred [21]. At each time point, participants identified the type of activity they were presently engaging in and rated state-level indicators of well-being, and, at the last assessment of each day a subjective assessment of overall workload was obtained (Table 2). Note that measures listed in Table 2 are only a subset used for analyses in this paper. For a full list of the items administered, please refer to the methods paper for the overarching study [24].

Table 2. Ecological momentary assessment measures administered over up to 14 days of data collection.

\begin{tabular}{|c|c|c|c|}
\hline Construct & Item(s) & Response Option(s) $^{1}$ & Time \\
\hline \multicolumn{4}{|l|}{ Activity } \\
\hline Activity type & $\begin{array}{l}\text { What were you doing right before starting this } \\
\text { survey? }\end{array}$ & $\begin{array}{l}\text { Work/school activities (e.g., paid labor, volunteer work, and } \\
\text { studying) } \\
\text { - Traveling (e.g., driving, riding in a car, walking) } \\
\text { Relaxing/chilling (e.g., passive leisure like watching Netflix, } \\
\text { listening to music) } \\
\text { - } \quad \text { Sleeping/napping } \\
\text { - } \quad \text { Cocializing (e.g., talking with friends/family) } \\
\text { - } \quad \text { paring for myself (e.g., eating, dressing, bathing, toileting, } \\
\text { - Caring for others (e.g., caring for your children and pets, if } \\
\text { you're caring for others as part of work this counts as } \\
\text { "work") } \\
\text { Doing housework/errands (e.g., paying bills, washing } \\
\text { dishes and clothes, exercising for health) } \\
\text { - Fun/play/leisure activities (e.g., active leisure like } \\
\text { exercising for fun, video games, reading for fun) } \\
\text { Other (If chosen, please specify) }\end{array}$ & All survey times \\
\hline
\end{tabular}


Table 2. Cont.

\begin{tabular}{|c|c|c|c|}
\hline Construct & Item(s) & Response Option(s) ${ }^{1}$ & Time \\
\hline \multicolumn{4}{|l|}{ Well-Being } \\
\hline Stress & How stressed are you right now? & 0 (Not at all stressed) to 100 (Extremely stressed) & All survey times \\
\hline Fatigue & At this moment, how tired do you feel? & 0 (Not at all) to 100 (Extremely) & All survey times \\
\hline Pain & $\begin{array}{l}\text { At this moment, how much bodily pain do you } \\
\text { have? }\end{array}$ & 0 (None) to 100 (Extreme pain) & All survey times \\
\hline $\begin{array}{l}\text { Positive } \\
\text { affect }\end{array}$ & $\begin{array}{l}4 \text { items: Average of mood ratings for "happy", } \\
\text { "content", "enthusiastic", "excited" }\end{array}$ & For each mood, 0 (not at all) to 100 (extremely) & All survey times \\
\hline $\begin{array}{l}\text { Negative } \\
\text { affect }\end{array}$ & $\begin{array}{l}4 \text { items: Average of mood ratings for "tense", } \\
\text { "upset", "sad", "disappointed" }\end{array}$ & For each mood, 0 (not at all) to 100 (extremely) & All survey times \\
\hline \multicolumn{4}{|l|}{ Workload } \\
\hline Task Load & $\begin{array}{l}\text { Average of } 6 \text { NASA-TLX items asking about } \\
\text { mental demand, physical demand, time } \\
\text { pressure, effort, performance satisfaction, and } \\
\text { frustration for activities over the whole day. }\end{array}$ & 0 to 100 sliding scale for each item, and the overall task load score & End of day \\
\hline Work hours & $\begin{array}{l}\text { (If worked) About how many hours did you } \\
\text { work? }\end{array}$ & Hours, whole number, 0 to 24 & End of day \\
\hline
\end{tabular}

${ }^{1}$ Activity examples were not in the actual item, but were explained during training and listed in a manual provided to participants.

\subsubsection{Activity Exposure}

At the beginning of every EMA survey, participants indicated the activity in which they were engaged immediately before the survey (sampling approach) [21] as opposed to reporting an activity that was engaged in for the greatest length of time in the hours prior (coverage) [21]. They were forced to choose only one activity option and prompted to choose the main or most important activity if several of them were being engaged in simultaneously. The sampling approach was used rather than a coverage method to minimize subjective selection of activities by the participants and further reduce recall bias. The activity question was adapted from a prior EMA study [26]. Possible activity responses were based on a taxonomy of activities created by occupational therapists based on their practice framework [27] and decided upon with expert review by occupational scientists. During baseline training, participants were given examples of types of activities within each category; these detailed examples were not presented with the answer choices to reduce word clutter on the phone screen.

The responses were conceptually sorted into the two primary constructs of highworkload and recovery based on inferences made from prior literature, the former including both work and non-work strenuous activities and the latter including leisure and rest activities. To do so, we emulated an approach used in prior studies where activities are sorted into categories based on their typical characteristics (e.g., watching television typically represents a "sedentary" behavior) [28].

High-workload tasks included "work/school" and "caring for others". "Work/school" was placed in this category because of the large body of literature conceptualizing work as a demanding task that requires recovery $[9,10]$. Caregiving is one of the few sources of nonworkplace demands that has been frequently investigated [13]. While many studies report adverse effects of caregiving [29,30], others have highlighted the benefits [31,32]. One broadly supported idea is that caregiving may have positive effects as long as workload is not too excessive (e.g., time demands being too high) [29,33]. We argued that given how often caregiving is conceptualized as a demand source that requires recovery periods [34], it conceptually belongs to the high-workload category. This classification was not meant to ignore the potential positive aspects of caregiving such as companionship and a sense of fulfillment [31], but to acknowledge the demands that often come with providing care for other individuals.

Recovery activities included "fun/play/leisure", "socializing", "relaxing/chilling", and "sleeping/napping". "Relaxing/chilling", and "sleeping/napping" were counted as recovery because both are often accompanied by increases in parasympathetic activity, which has been conceptualized as a defining feature of rest [35]. "Fun/play/leisure" and 
"socializing" were also subsumed under recovery because both are forms of leisure [36], which is an often-cited form of recovery [10].

Any activity choice that did not fit into high-workload or recovery groupings was placed into an "unclassified" category. "Doing housework/errands" was one activity placed into this category because there is limited published research to provide a clear interpretation of these tasks. For example, "cleaning" is considered restful by some and demanding by others, making it difficult to define as either high-workload or recovery without further understanding an individual's context. Participants also had an option to specify "other activities" not covered by the a priori activity response options using an open-ended response. These responses were assigned to one of the three categories during a post hoc review process. For example, an open-ended response "vigorous exercise" would fit under "high-workload" because of the short-term demand, though it may have a long-term benefit.

\subsubsection{Perceived Workload}

We administered additional measures explicitly tapping participants' perceptions of workload at the end of each day to validate that our EMA derived high-workload and recovery activity frequency measures had the expected associations with end-of-day workload measures. Survey questions were selected from validated global measures or those that had been used successfully in previous EMA studies. Task load is the level of difficulty an individual encounters when executing tasks [37] and was assessed with an adapted version of the National Aeronautics and Space Administration Task Load Index (NASA-TLX) [38]. Like the original TLX, we also used six items addressing different contributors to task load, but changed the period being inquired about to a whole day rather than a particular task. In the nursing literature, there has been some evidence supporting the validity of use of the TLX items to cover entire periods instead of particular tasks, specifically whole work shifts [39]. The NASA-TLX provides an overall task load score based on the summation (or equivalently, averaging) of an individual's perception of mental demand, physical demand, temporal demand, performance, effort, and frustration level [12]. While a weighting scheme accounting for individual variation in the extent to which each dimension of demands contributes to overall task load was utilized for the original TLX, a review found that raw sums (or equivalently, simple average) appeared just as valid [12]. Total hours worked served as a behavioral measure of general workload over the day.

\subsubsection{Well-Being Experiences}

Participants' momentary well-being experiences were measured using a variety of state-level factors including affect, working memory, stress, fatigue, and pain-all of which are core well-being concepts encapsulated in the health status section of NIOSH's new Worker Well-being Questionnaire (NIOSH WellBQ) [40]. For positive and negative affect, items were taken from the "Stress and Working Memory" (SAWM) study [41], which were adapted from the Positive and Negative Affect Schedule (PANAS) [42] by changing the period referenced (e.g., asking about emotions in the moment) and the mood items used. The items for fatigue and pain were taken from prior a EMA study [43], where they were derived from the Brief Fatigue Inventory [44] and Brief Pain Inventory, respectively [45]. Our item for stress was used in a prior EMA study [46].

\subsubsection{Scoring of Measures}

Various scoring approaches were used for different measures. For single item assessments of stress, fatigue, pain, and work hours, there was no score calculation step. The workload, affect, and activity exposure measures however did involve the calculation steps described prior. Scoring algorithms for workload, positive/negative affect, and high workload activity frequency were decided prior to reviewing the dataset. For calculation of recovery frequency however, prior to looking at the data, a scoring approach was used 
where "relaxing" and "leisure" were treated as separate forms of recovery. After review of the initial draft, one of the co-authors commented that collapsing relaxing and leisure under the umbrella of recovery made more sense. Thus, scoring for recovery exposure was changed to include both relaxing and leisure activities.

\subsection{Statistical Analyses}

To calculate daily activity frequencies within the high-workload and recovery categories, we divided the number of times people reported engaging in a particular activity type by the number of EMA assessments taken [47]. For example, if a participant completed six surveys in a day and reported engaging in activities within the high-workload category during three surveys, then the relative frequency of high-workload for that day would be $3 / 6=0.5$. Frequencies were only calculated for days where participants completed four or more surveys.

We conducted intra-person correlational tests to investigate the associations of our EMA derived daily activity frequencies with end of day workload and well-being measures. In addition to daily activities, we hypothesized that weekends would have lower highworkload and higher recovery activity frequencies than did days during a traditional 5-day work week. Mixed-effects modeling was used with day of the week as the only predictor, the intercept as the dependent variable's random effect, and frequency of activity groupings (e.g., high-workload and recovery) as the dependent variable. Models were run with the "lme4" package in the statistical software R [48]. Mixed modeling was used to account for the nested nature of the data (multiple days nested in an individual) while testing hypotheses involving multilevel categorical predictors (e.g., day of week) [49]. We chose Sunday as the reference for ease of comparison, as we anticipated that it would have the greatest frequency of recovery and lowest frequency of high-workload activities. Given that $p$ values of parameters from mixed models may be biased because of the inherent uncertainty in the degrees of freedom to specify for calculations [50], especially when the data structure is complex or the dataset is unbalanced, we used bootstrapping to derive standard errors for the parameters and perform significance testing [50,51]. Bootstrapping was also used to account for potential non-normality in the mixed model residuals using the "method = boot" argument available in the "Ime4" package. The decision to perform mixed models was done a priori, to allow for comparison of the mean values of high workload and recovery across different days of the week, and have a corresponding indication of statistical significance. The initial plan was to just present mean values of high workload/recovery/unclassified by day of week, but it seemed unsatisfactory to not be able to comment on statistical significance of the differences.

The "power.rmcorr" function in $\mathrm{R}$ was used to estimate the statistical power to detect repeated measures correlations [52]. Based on prior daily diary research, we assumed an intraclass coefficient of 0.5 for the nesting of repeated observations in individuals $[53,54]$ for the power calculations. A priori sample size calculations suggested that a sample size of 30 with 13 observations per individual would yield $82 \%$ power to detect within-person effect sizes of 0.15 with $\alpha=0.05$ (a small effect as per Cohen's conventions [55].

\section{Results}

Analyses were conducted on data from a total of 45 participants from the multisite study who identified as workers. The participants primarily worked full-time, had an average age of $40.1(\mathrm{SD}=12.7)$ years, and were heterogenous with respect to gender, ethnicity, education, and annual income (Table 3). Participants were not required to report their vocations, but occupations reported include lawyer, engineer, housekeeper, teacher, and security guard. The median EMA completion percentage was $92 \%$, and four or more EMA surveys were completed on $83 \%$ of all data collection days across the participants. The average number of days meeting the minimum threshold for inclusion of four EMA surveys was 12.5 days per participant. The final dataset included a total of 3352 EMA datapoints across 564 valid days. In post hoc power analyses, our sample of 45 participants 
with 12.5 observations per individual yielded $84 \%$ power to detect within-person effect sizes of 0.13 with $\alpha=0.05$.

Table 3. Demographic characteristics of our working sample $(n=45)$.

\begin{tabular}{lcc}
\hline \multicolumn{1}{c}{ Characteristic } & $n$ & Mean (SD) or Percent (\%) \\
\hline Age (years) & 45 & $40.1(12.7)$ \\
\hline Gender & & \\
Male & 21 & $47 \%$ \\
Female & 24 & $53 \%$ \\
\hline Ethnicity & & \\
White & 20 & $44 \%$ \\
Latino/x & 10 & $22 \%$ \\
African American & 7 & $16 \%$ \\
Multi-ethnic & 4 & $9 \%$ \\
Other & 4 & $9 \%$ \\
\hline Employment status & & \\
Full-time & 35 & $78 \%$ \\
Part-time & 10 & $22 \%$ \\
\hline Education & & \\
High school grad or less & 5 & $11 \%$ \\
Some college, no degree & 6 & $2 \%$ \\
Associate's degree & 1 & $40 \%$ \\
Bachelor's degree & 18 & $33 \%$ \\
Graduate degree & 15 & $20 \%$ \\
\hline Annual household income & & $23 \%$ \\
$<\$ 50,000$ & 9 & $18 \%$ \\
\$50,000-\$99,999 & 10 & $7 \%$ \\
$\geq \$ 100,000$ & 15 & \\
Do not wish to provide & 8 & \\
Do not know & & \\
\hline & & \\
& & \\
\hline
\end{tabular}

The distribution of responses within each of the activity types is provided in Table 4 . Approximately half of the datapoints were equally split between work/school $(25.8 \%)$ and relaxing/chilling $(22.0 \%)$. One-third of the responses were split between sleeping/napping $(13.0 \%)$, housework/errands $(11.8 \%)$, and self-care activities $(11.2 \%)$. A total of 920 responses were categorized as high-workload, 1452 as recovery, and 980 as unclassified. High-workload activities had a lower average daily relative frequency $(0.28, \mathrm{SD}=0.25)$ compared to the average daily relative frequency of recovery activities $(0.43, \mathrm{SD}=0.25)$.

Table 4. Frequency distribution of activity types across all datapoints $(n=3352)$.

\begin{tabular}{cc}
\hline Activity Type & Frequency (\%) \\
\hline Work/school activities & $866(25.8 \%)$ \\
Relaxing/chilling & $739(22.0 \%)$ \\
Sleeping/napping & $437(13.0 \%)$ \\
Doing housework/errands & $396(11.8 \%)$ \\
Caring for myself & $374(11.2 \%)$ \\
Fun play /leisure activities & $191(5.7 \%)$ \\
Traveling & $160(4.8 \%)$ \\
Socializing & $85(2.5 \%)$ \\
Caring for others & $54(1.6 \%)$ \\
Other & $50(1.5 \%)$ \\
\hline
\end{tabular}

Full between and in-person correlation matrices are shown in Appendices A and B respectively. Note that the correlations shown in Table 5 are only the subset of associations from Appendix A that were of interest in this paper, along with their confidence intervals. 
We did not address between-person correlations in this paper, as the within-person context was of interest, and we only had sufficient power to investigate within-person questions and not between-person ones. Thus, between-person associations shown in Appendix A should be cautiously interpreted, and were included to highlight the distinction among between- and within-person relationships.

Table 5. Within-person correlations among daily frequency of activity categories and measures of workload and well-being. Values in parentheses represent $95 \%$ confidence intervals.

\begin{tabular}{|c|c|c|c|c|c|c|c|}
\hline & $\begin{array}{l}\text { Overall Task } \\
\text { Load }\end{array}$ & Work Hours & Stress & Fatigue & Pain & Positive Affect & Negative Affect \\
\hline $\begin{array}{l}\text { High workload } \\
\text { activity frequency }\end{array}$ & $\begin{array}{c}0.42 \\
(0.34,0.49)\end{array}$ & $\begin{array}{c}0.31 \\
(0.21 .04)\end{array}$ & $\begin{array}{c}0.34 \\
(0.26,0.41)\end{array}$ & $\begin{array}{c}0.11 \\
(0.03,0.2)\end{array}$ & $\begin{array}{c}0.02 \\
(-0.07 \quad 0.11)\end{array}$ & $\begin{array}{c}-0.15 \\
(-0.23-0.07)\end{array}$ & $\begin{array}{c}0.21 \\
(0.13,0.29)\end{array}$ \\
\hline Recovery activity & $\begin{array}{c}(0.34,0.49) \\
-0.37 \\
(-0.04-0,29)\end{array}$ & $\begin{array}{c}(0.21,0.4) \\
-0.14 \\
(-025-0,04)\end{array}$ & $\begin{array}{c}(0.20,0.41) \\
-0.34\end{array}$ & $\begin{array}{c}(0.0,0.2) \\
-0.10 \\
(-019-0\end{array}$ & $\begin{array}{c}-0.07,0.11) \\
-0.06\end{array}$ & $\begin{array}{c}0.14 \\
0 .\end{array}$ & $\begin{array}{c}(0.13,0.29) \\
-0.22 \\
(-03-0\end{array}$ \\
\hline Unclassified & $\begin{array}{c}-0.08 \\
(-0.16,0.01)\end{array}$ & $\begin{array}{c}-0.17 \\
(-0.27,-0.07)\end{array}$ & $\begin{array}{c}-0.02 \\
(-0.11,0.07)\end{array}$ & $\begin{array}{c}-0.02 \\
(-0.11,0.06)\end{array}$ & $\begin{array}{c}0.04 \\
(-0.04,0.13)\end{array}$ & $\begin{array}{c}0.02 \\
(-0.07,0.1)\end{array}$ & $\begin{array}{c}-0.01 \\
(-0.1,0.08)\end{array}$ \\
\hline
\end{tabular}

Except for pain, all associations among the daily relative frequencies for high-workload and recovery activities with measures of workload and well-being were in line with our hypotheses (Table 5). High-workload activity frequency had a moderate positive association with overall task load $(\mathrm{r}=0.42)$, work hours $(\mathrm{r}=0.31)$, and stress $(\mathrm{r}=0.34)$, whereas recovery activity frequency had a moderate negative association with overall task load $(r=-0.37)$ and stress $(r=-0.34)$. Fatigue, positive affect, and negative affect were weakly associated with the two categories, and the two groupings had opposite directions for each. Unclassified activity frequency had only a weak negative association with work hours $(r=-0.17)$, with no other associations with workload or well-being.

The daily relative frequencies of high-workload and recovery activities had nearly opposite patterns when examining their distributions across days of the week (Figure 1). Recovery activities accounted for a clear majority of the activities (i.e., $>0.50$ ) on the weekend and were slightly more prevalent than high-workload activities on Mondays and Fridays. High-workload and recovery activity frequencies were balanced through the middle of the week. Mixed model results for the daily activity frequency measures were consistent with our hypotheses. High-workload activities were more frequent on weekdays compared to Sunday, and recovery activities were less frequent on weekdays compared to Sunday (Table 6). The mean frequency of unclassified activities was only different from Sunday on Monday through Wednesday.

Table 6. Day-of-week differences in activity frequencies. Values in parentheses represent $95 \%$ confidence intervals.

\begin{tabular}{ccccc}
\hline Day & $\begin{array}{c}\text { Number of } \\
\text { Observations }\end{array}$ & $\begin{array}{c}\text { High-Workload } \\
\text { Frequency } \\
\text { Beta, (95\% CI) }\end{array}$ & $\begin{array}{c}\text { Recovery } \\
\text { Frequency } \\
\text { Beta, (95\% CI) }\end{array}$ & $\begin{array}{c}\text { Unclassified } \\
\text { Frequency } \\
\text { Beta, (95\% CI) }\end{array}$ \\
\hline Sunday & 89 & Reference & Reference & Reference \\
Monday & 87 & $0.24,(0.18,0.29)$ & $-0.16,(-0.22,-0.1)$ & $-0.08,(-0.14,-0.02)$ \\
Tuesday & 106 & $0.29,(0.23,0.34)$ & $-0.21,(-0.28,-0.15)$ & $-0.07,(-0.13,-0.02)$ \\
Wednesday & 105 & $0.32,(0.26,0.38)$ & $-0.24,(-0.3,-0.18)$ & $-0.09,(-0.14,-0.03)$ \\
Thursday & 107 & $0.26,(0.19,0.31)$ & $-0.2,(-0.26,-0.14)$ & $-0.05,(-0.11,0.01)$ \\
Friday & 104 & $0.22,(0.16,0.28)$ & $-0.17,(-0.22,-0.11)$ & $-0.05,(-0.11,0.00)$ \\
Saturday & 78 & $0.00(-0.06,0.06)$ & $0.01,(-0.05,0.08)$ & $-0.01,(-0.07,0.05)$ \\
\hline
\end{tabular}




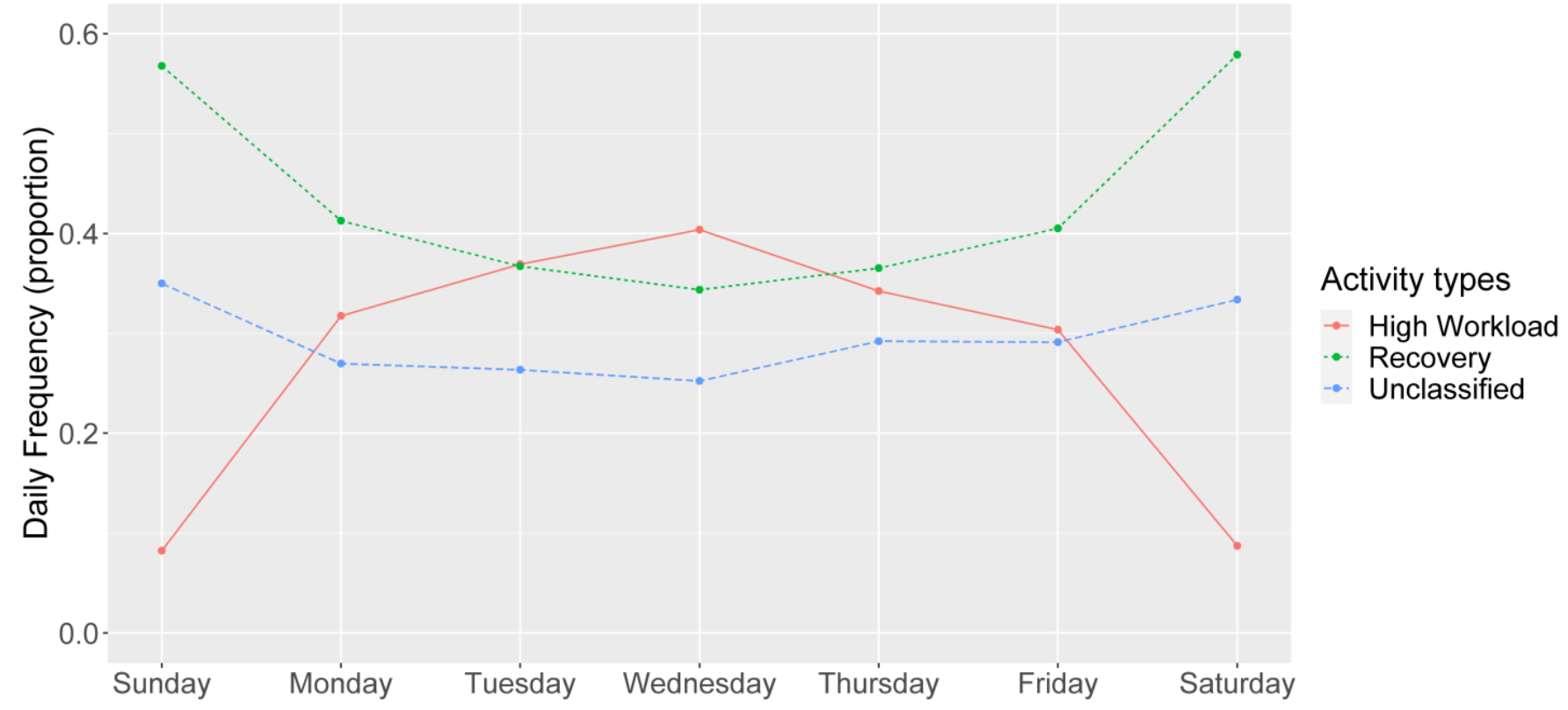

Figure 1. Distribution of activity frequencies, by day of week.

Measures of well-being showed less consistent patterns of mean level differences across the days of the week (Figure 2). Stress was the only state-level well-being measure that demonstrated fluctuations across days of the week, with a pattern comparable to that of high-workload activity frequency. A slight upward trend in fatigue was noted across the week, and participants generally reported low levels of pain, minimal negative affect, and high positive affect, measures that all remained relatively stable across the week.

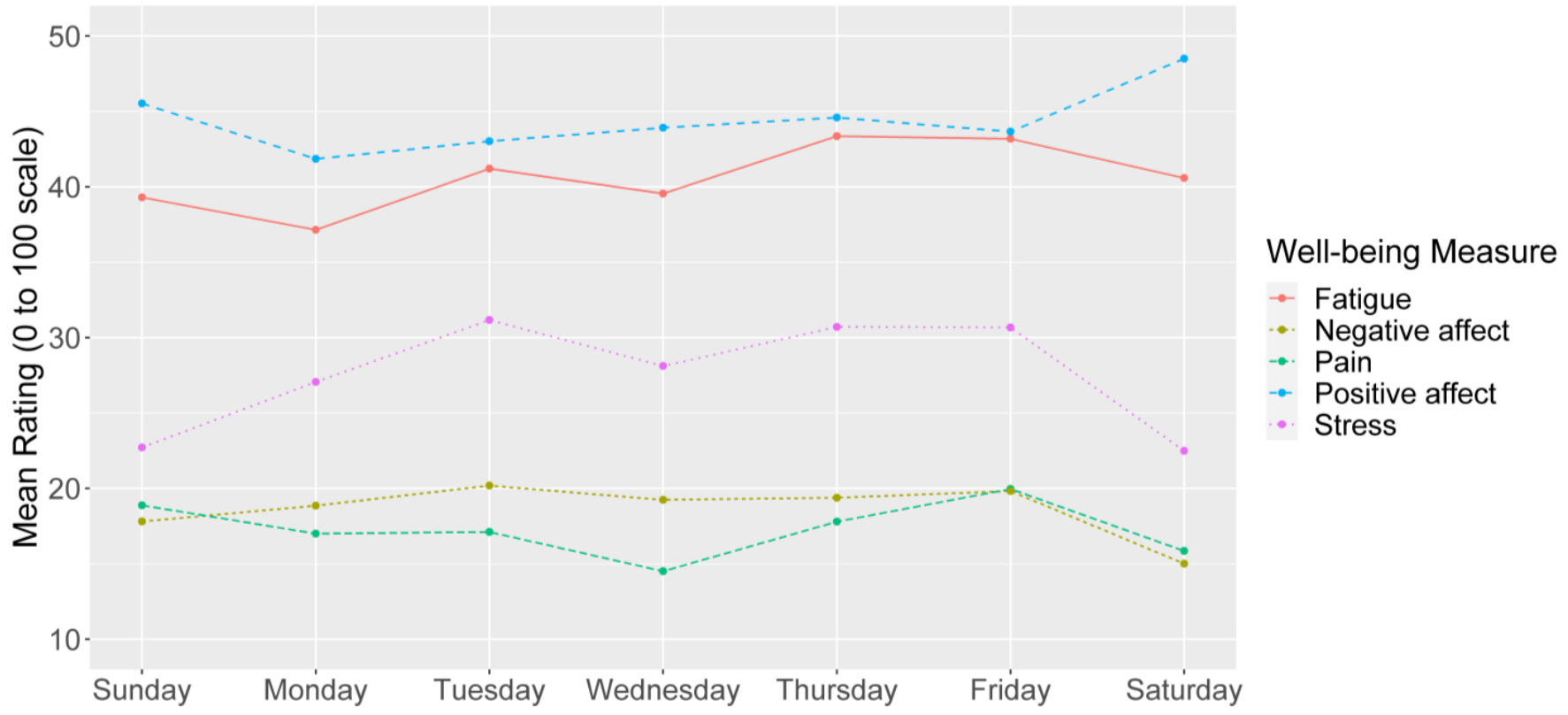

Figure 2. Average ratings of state-level well-being, by day of week.

\section{Discussion}

\subsection{Principal Findings}

Our results supported the usefulness of our EMA-derived daily activity frequency measures, with one piece of supporting evidence being our observation of weekend versus weekday differences in theoretically expected directions. Though not hypothesized a 
priori, mean high-workload activity frequency steadily increased from Monday to Wednesday and then decreased on Thursday and Friday. Conversely, mean recovery activity frequency steadily decreased from Monday to Wednesday and increased on Thursday. This is consistent with the finding that fatigue, a possible proxy measure of the amount of workload relative to recovery experienced, was found to peak midweek and then decrease for workers [56]. Whole day workload and recovery by day of week has not yet been formally examined.

Results of within-person correlation tests also generally provided evidence supporting the trustworthiness of our daily activity measures. Frequency of unclassified activities had a significant but weak association with work hours $(\mathrm{r}=-0.17, p=0.001)$. This relationship may have been driven by slight increases in engagement in unclassified activities (e.g., housework/errands) on the weekends when high-workload activities decreased. Despite this association, unclassified activities were not found to be related to measures of task load or any of the well-being factors, further indicating that deeper examination of contextual factors underlying these activities is needed to better understand their impact either on demand or recovery as a component of a worker's day.

In contrast to the lack of association in unclassified activities, daily frequencies of high-workload and recovery activities followed the hypothesized associations with wellbeing measures. This finding provides preliminary support that an EMA derived whole day metric of activities may be useful for exploring the holistic impact of both work and non-work periods. Across the correlations among high-workload and recovery activities with measures of workload and well-being, $86 \%$ were consistent with our hypotheses providing strong evidence of convergent validity. Convergent validity is considered to be adequate if at least $75 \%$ of hypothesized correlations are empirically supported $[57,58]$.

Given the number of statistical tests conducted, there is a chance of spurious associations. We conducted approximately 39 statistical tests, which included 21 within-person correlation tests and 18 beta parameter tests in mixed models. This total includes tests for unclassified activities that were done for exploratory purposes as opposed to hypothesis testing. Assuming an alpha of 0.05 , approximately $2(39 \times 0.05)$ of the "significant" findings as per confidence intervals may have been spurious associations. Given how small this number is however relative to the number of associations we found aligned with our hypotheses, the overall findings of this pilot work provide strong preliminary evidence in supporting the evaluation of within-person relationships among workload/recovery across both work and non-work settings and measures of worker well-being.

\subsection{Implications for $E M A$ in Worker Health Research}

While the relationship between workload/recovery and well-being has long been researched $[15,18]$, the novelty of this study lies in the development of methods to assess high-workload and recovery activity exposure across both work and non-work settings using EMA methods. Studying the experience of high-workload and recovery activities by considering both work and non-work contexts matches well with NIOSH's intent to support workers of the future through its TWH initiative [1,6-8]. When workload and recovery are examined only in work or non-work scenarios, researchers are likely to attain an incomplete picture of total exposure and a fragmented depiction of how well-being outcomes arise. The actual relationships found between whole day activity frequencies and various well-being measures were generally in the expected directions. This provides preliminary evidence that measures with a coverage period comprising both work and non-work can provide meaningful information.

From a psychometric standpoint, no prior studies have formally validated daily activity frequencies calculated from a single EMA activity engagement item. Our results imply that our measurement approach, involving classification of a broad range of activity choices and tallying of the number of reports of particular activities in a day, may be appropriate for specific activity types. Activity frequencies derived from a single EMA activity engagement item would likely be particularly useful in studies already planning to 
administer multiple EMA signals daily for several days. With minimal additional burden to participants, adding a single activity engagement item would allow researchers to gauge time use in an activity believed to be relevant to the primary construct of interest. For instance, in EMA studies investigating links between momentary patient reported outcome data and ambulatory physiological measures (e.g., blood pressure, blood glucose) in workers, a single activity item could potentially allow for exploration of questions such as how time spent in particular activities (e.g., work or leisure) is associated with the values of physiological measures on the same day.

EMA based time use measurement can also potentially be used by organizational leadership to approximately gauge time employees spend in high-workload and recovery activities over entire days, especially if they are already using EMA to measure other variables of interest such as ergonomic positioning or mood [59]. For instance, employers can work to identify the circumstances that contribute to excessive exposure to high workload relative to recovery. This imbalance may occur across all workers during certain days of the week or seasons of the year. Employers can also investigate relationships between whole day high workload/recovery and other within person measures of interest such as productivity or frequency of job errors on a particular day.

The utility of measuring daily workload directly (e.g., with the TLX) compared to assessing engagement in high-workload activities through EMA requires further research. Theoretically, the former requires that participants make a judgement of how demanding tasks across the day felt, while the latter requires them to just report activities that they engaged in, from which high workload exposure is calculated. Which is more useful may depend on the research question (e.g., if judgement-based vs. activity- report derived workload ratings are of interest), and which is found to have a greater relationship with the outcome(s) of interest (e.g., stress).

\subsection{Limitations and Future Directions}

Findings of this study should be considered within the context of this work as a pilot study. This includes an acknowledgement that this work is not intended to indicate conclusive relationships among whole-day exposures and well-being, but to serve as preliminary support for a process that could be used to examine these relationships.

Moreover, it should be noted that data collection was limited to individuals who had type 1 diabetes and were experiencing the COVID-19 pandemic and its associated social distancing requirements during data collection. Replication of this process with larger samples and within other worker populations and settings is needed to confirm our preliminary findings as more conclusive evidence of the relationships suggested in this study. Due to similarities in the implications of having chronic conditions, we anticipate that our T1D population may be somewhat similar to other worker populations with chronic conditions, suggesting the potential for future studies to generalize our study findings. For instance, the Chronic Disease Self-Management program, a widely used intervention for chronic conditions, assumes that patients with different chronic diseases have similar self-management problems and disease related tasks [60], which can include following complex treatment regimens, self-monitoring one's condition(s), and making decisions about when/how to receive professional treatment [61]. All these responsibilities are additional potential sources of workload, which may in part explain why management of chronic conditions in general is frequently perceived as intrusive to people's daily lives [62]. As additional evidence of the commonalities between chronic conditions, research is often conducted on populations with any chronic condition $[63,64]$. Nearly $45 \%$ of all Americans suffer from at least one chronic condition [65]. While our T1D population is potentially similar to populations with chronic conditions generally, they may have more commonalities with people with type 2 diabetes (T2D). Thus, our findings may generalize more easily to people with $\mathrm{T} 2 \mathrm{D}$ as compared to populations with chronic conditions generally. T1D and T2D have different etiologies, and T2D is the much more common of the two, with a prevalence of $8.5 \%$ in the U.S as of 2017 as compared to $0.5 \%$ for 
T1D [66]. However, they share similar management approaches (e.g., insulin therapy [67]) which can often serve as sources of distress [68]. In research studies, participants with both T1D and T2D are often pooled together $[67,68]$.

In addition to limitations inherent in a pilot study, because activity engagement was a secondary measure within the primary study, precision for the EMA activity item was perhaps limited. Specifically, to minimize participant burden only nine broad activity choices were provided, and no follow-up questions were asked. The possible realm of activities are likely much more nuanced and capturing contextual factors and relative meaning to each individual might increase the ability to more precisely categorize activities as high-workload or recovery. One approach that may be worth testing in future studies is asking participants to first choose a general category of activities that best matches what they had been doing immediately prior to the survey (e.g., housework), and then use branching logic to ask about the specific activity done (e.g., washing dishes or vacuuming). This would allow for more detailed participant activity reports while reducing screen clutter. An additional semantic differential question allowing participants to rate the activity on a spectrum from high-workload to recovery could begin to fill the gap in understanding individual perspectives on activities, particularly those falling within our unclassified category.

Because the precision for our EMA activity item was limited we could not account for individual variation in context, and misclassification during conceptual sorting of activity types into high workload or recovery may have occured. For instance, if a participant reported "fun/play/leisure" this activity would always fall under the recovery category. However, "fun/play/leisure" in the form of a friendly board game could have been highstress if it had evolved into cutthroat competition. As such, implicit in our conceptual sorting scheme was a certain degree of error that likely created a deviation from true highworkload/recovery activity exposure. A benefit of this rough sorting heuristicwas that it only required a single EMA item asking about type of activity engagement, and our results indicate that the sorting was good enough to capture relationships with the well-being measures. In future studies, increased accuracy could be achived using a more refined sorting of activities into high-workload and recovery bins may be possible if, in addition to a question about type of activity engaged in, there is also a rating of the workload associted with that activity, as suggested in the prior paragraph. The downside of this approach is the added respondent burden.

EMA measures are not formally validated as often as one time cross-sectional measures [69], so another study limitation to consider is that evidence of validity for EMA assessments used in this paper comes in the less definite forms of being adapted from validated global measures, and/or being successfully used in prior studies. While the approach of arguing for the validity of EMA assessments based on derivation from an establish global measure is often taken [43,70], it is also common for EMA studies to rely on face validity for some items [46,71]. The full versions of global measures often cannot be used in the EMA context due to excessive length, so adaption to shorter versions is often required [70]. While some work has been done to formally validate these shortened versions [72], such efforts often focus on validation in the between-person context and not within-person [69], like in our work.

Worker well-being is a broad multi-dimensional concept, and this pilot study did not address all aspects of well-being. We were limited in our choice of well-being measures to items included as part of the overarching study investigating the relationship between a variety of variables and blood glucose. Well-being variables that were included were general enough to be appliable to a large segment of workers, as evidenced by their inclusion in the NIOSH WellBQ, but do not comprehensively capture well-being. Future studies may be needed to investigate how high-workload and recovery activity exposure over whole days relate to other aspects of well-being (e.g., sleep quality, life satisfaction) not covered in this study. 
Two further limitations are noted in our statistical approach. Firstly, within the context of worker well-being, researchers and practitioners are commonly interested in examining between-person questions, such as how workers with different job classifications and/or work schedule arrangements differ in their mean exposure to high workload and recovery activities. This pilot study was designed to provide preliminary support for measuring within-person relationships among activities and well-being, and did not examine betweenperson contexts in part because we were insufficiently powered to do so. Given that our findings supported general within-person hypotheses, future studies could examine feasibility for using EMA to create between person-level outcomes (e.g., averages over the entire study period) that could support between-person analyses. For instance, future studies might be able to conduct concurrent validity testing of study period averages of the daily activitiy frequencies (between-person metrics) by comparing their values to those attained from full questionnaires, such as the newly released NIOSH WellBQ. Secondly, we used the standard approach in longitudinal data analyses of assuming that our missing data were missing at random [73], which may have biased our results. There is a possibility that data was not missing at random. For instance, high workload engagements may have been undercounted because some participants may be less likely to answer surveys during those activities. Work on modeling data not missing at random in the longitudinal context is ongoing [73].

A final limitations in this pilot work is that our results did not allow us to assess our theoretical assertion that, when workload and recovery are examined only in work or non-work scenarios, researchers are likely to attain an incomplete picture of total exposure and a fragmented depiction of how well-being outcomes arise. Instead, our results provide evidence supporting one potential way to measure workload/recovery across both work and non-work. Future research, posssibly using the EMA assessment used here, is needed to compare how/if whole day and work specific measures of workload/recovery differ in their associations with well-being. Our theoretical assertion would be supported if the whole day version has stronger associations with well-being relative to assessment only of work periods.

\section{Conclusions}

In this pilot study, we found that measures of the frequency of high-workload and recovery activities over a whole day generally had the expected associations with same day well-being measures. More frequent engagement in high-workload activities was associated with worse well-being experiences including higher stress and lower positive affect. Conversely, greater recovery activity frequency was mostly associated with better well-being including lower stress and higher positive affect. Activity frequency measures also had anticipated associations with day of the week whereby high-workload activities peaked during the middle of the week and recovery activity frequency was more common on the weekends. Our results provide preliminary validity evidence for measures of highworkload and recovery activity exposure across a whole day that covers both work and nonwork periods. This assessment of both work and non-work factors may facilitate strategies for identifying job classifications, work schedules, or individual workers who may be most at-risk for negative impacts on well-being. Application of these EMA techniques may serve as a basis for employers to develop policies or programs to support health and well-being across their workforce.

Author Contributions: Conceptualization, R.H., E.A.P. and S.C.R.; methodology, R.H., C.L.P.V., H.J, and S.S.; software, R.H.; formal analysis, R.H., C.L.P.V., H.J. and S.S.; resources, E.A.P.; writingoriginal draft preparation, R.H., E.A.P. and S.C.R.; writing-review and editing, R.H., E.A.P., C.L.P.V., H.J., S.S., D.S.-M. and S.C.R.; supervision, S.C.R.; funding acquisition, E.A.P., D.S.-M. and R.H. All authors have read and agreed to the published version of the manuscript.

Funding: This research was funded by the National Institutes of Health, National Institute of Diabetes and Digestive and Kidney Diseases, grant number NIH/NIDDK 1R01DK121298-01 and the Pilot 
Project Research Training Program of the Southern California NIOSH Education and Research Center, grant number T42 OH008412.

Institutional Review Board Statement: The study was conducted according to the guidelines of the Declaration of Helsinki, and approved by the Institutional Review Board of the University of Southern California (Study ID: HS-18-01014; 2 January 2019).

Informed Consent Statement: Informed consent was obtained from all subjects involved in the study.

Data Availability Statement: The data that support the findings of this study are available from the corresponding author, R.H., upon reasonable request.

Acknowledgments: We thank all the Los Angeles and New York members of the FEEL-T1D data collection team.

Conflicts of Interest: The authors declare no conflict of interest. There is no external funding authority involved and hence the funders had no role in the design of the study; in the collection, analyses, or interpretation of data; in the writing of the manuscript, or in the decision to publish the results.

\section{Appendix A}

Table A1. Between-person intercorrelation matrix.

\begin{tabular}{|c|c|c|c|c|c|c|c|c|c|c|}
\hline & $\begin{array}{l}\text { High Workload } \\
\text { Freq. }\end{array}$ & $\begin{array}{l}\text { Recovery } \\
\text { Freq. }\end{array}$ & $\begin{array}{l}\text { Un-Classified } \\
\text { Freq. }\end{array}$ & Stress & Fatigue & Pain & $\begin{array}{c}\text { Positive } \\
\text { Affect }\end{array}$ & $\begin{array}{c}\text { Negative } \\
\text { Affect }\end{array}$ & $\begin{array}{l}\text { Task } \\
\text { Load }\end{array}$ & $\begin{array}{l}\text { Work } \\
\text { Hours }\end{array}$ \\
\hline High & 1 & & & & & & & & & \\
\hline Workload & $p<0.001$ & & & & & & & & & \\
\hline Recovery & -0.36 & $\begin{array}{c}1, \\
n<0001\end{array}$ & & & & & & & & \\
\hline Freq. & $\begin{array}{c}p=0.016 \\
-0.39\end{array}$ & $\begin{array}{c}p<0.001 \\
-0.72\end{array}$ & 1 & & & & & & & \\
\hline Un-classified & $p=0.008$ & $p<0.001$ & $p<0.001$ & & & & & & & \\
\hline Stress & $\begin{array}{c}0.44 \\
p=0.003\end{array}$ & $\begin{array}{c}-0.19 \\
p=0.206\end{array}$ & $\begin{array}{c}-0.13 \\
p=0.377\end{array}$ & $\begin{array}{c}1 \\
p<0.001\end{array}$ & & & & & & \\
\hline Fatigue & $\begin{array}{c}0.33 \\
p=0.028\end{array}$ & $\begin{array}{c}-0.08 \\
p=0.621\end{array}$ & $\begin{array}{c}-0.17 \\
p=0.271\end{array}$ & $\begin{array}{c}0.57 \\
p<0.001\end{array}$ & $\begin{array}{c}1 \\
p<0.001\end{array}$ & & & & & \\
\hline Pain & $\begin{array}{c}0.22 \\
p=0.142\end{array}$ & $\begin{array}{c}-0.31 \\
p=0.038\end{array}$ & $\begin{array}{c}0.14 \\
p=0.355\end{array}$ & $\begin{array}{c}0.44 \\
p=0.003\end{array}$ & $\begin{array}{c}0.50 \\
p<0.001\end{array}$ & $\begin{array}{c}1, \\
p<0.001\end{array}$ & & & & \\
\hline $\begin{array}{c}\text { Positive } \\
\text { Affect }\end{array}$ & $\begin{array}{c}0.22 \\
p=0.140\end{array}$ & $\begin{array}{c}0.01 \\
p=0.930\end{array}$ & $\begin{array}{c}-0.18 \\
p=0.240\end{array}$ & $\begin{array}{c}-0.10 \\
p=0.503\end{array}$ & $\begin{array}{c}-0.05 \\
p=0.743\end{array}$ & $\begin{array}{c}-0.09 \\
p=0.560\end{array}$ & $\begin{array}{c}1, \\
p<0.001\end{array}$ & & & \\
\hline $\begin{array}{c}\text { Negative } \\
\text { Affect }\end{array}$ & $\begin{array}{c}0.32 \\
p=0.031\end{array}$ & $\begin{array}{c}-0.18 \\
p=0.227\end{array}$ & $\begin{array}{c}-0.06 \\
p=0.711\end{array}$ & $\begin{array}{c}0.73 \\
p<0.001\end{array}$ & $\begin{array}{c}0.40 \\
p=0.006\end{array}$ & $\begin{array}{c}0.45 \\
p=0.002\end{array}$ & $\begin{array}{c}-0.11 \\
p=0.459\end{array}$ & $\begin{array}{c}1 \\
p<0.001\end{array}$ & & \\
\hline Task Load & $\begin{array}{c}0.51 \\
p<0.001\end{array}$ & $\begin{array}{c}-0.30 \\
p=0.043\end{array}$ & $\begin{array}{c}-0.08 \\
p=0.610\end{array}$ & $\begin{array}{c}0.73 \\
p<0.001\end{array}$ & $\begin{array}{c}0.34 \\
p=0.022\end{array}$ & $\begin{array}{c}0.38 \\
p=0.010\end{array}$ & $\begin{array}{c}0.10 \\
p=0.499\end{array}$ & $\begin{array}{c}0.49 \\
p=0.001\end{array}$ & $\begin{array}{c}1, \\
p<0.001\end{array}$ & \\
\hline Work Hours & $\begin{array}{c}0.21 \\
p=0.172\end{array}$ & $\begin{array}{c}0.02 \\
p=0.874\end{array}$ & $\begin{array}{c}-0.17 \\
p=0.260\end{array}$ & $\begin{array}{c}0.10 \\
p=0.532\end{array}$ & $\begin{array}{c}0, \\
p=0.988\end{array}$ & $\begin{array}{c}-0.11 \\
p=0.495\end{array}$ & $\begin{array}{c}0.04 \\
p=0.793\end{array}$ & $\begin{array}{c}-0.05 \\
p=0.734\end{array}$ & $\begin{array}{c}0.09 \\
p=0.576\end{array}$ & $\begin{array}{c}1 \\
p<0.001\end{array}$ \\
\hline
\end{tabular}

\section{Appendix B}

Table A2. Within-person intercorrelation matrix.

\begin{tabular}{|c|c|c|c|c|c|c|c|c|c|c|}
\hline & $\begin{array}{l}\text { High Workload } \\
\text { Freq. }\end{array}$ & $\begin{array}{l}\text { Recovery } \\
\text { Freq. }\end{array}$ & $\begin{array}{l}\text { Un-Classified } \\
\text { Freq. }\end{array}$ & Stress & Fatigue & Pain & $\begin{array}{c}\text { Positive } \\
\text { Affect }\end{array}$ & $\begin{array}{c}\text { Negative } \\
\text { Affect }\end{array}$ & $\begin{array}{l}\text { Task } \\
\text { Load }\end{array}$ & $\begin{array}{l}\text { Work } \\
\text { Hours }\end{array}$ \\
\hline High & 1 & & & & & & & & & \\
\hline Workload & $p<0.001$ & & & & & & & & & \\
\hline Recovery & -0.67 & 1 & & & & & & & & \\
\hline Freq. & $p<0.001$ & $p<0.001$ & & & & & & & & \\
\hline Un-classified & $\begin{array}{c}-0.46 \\
p<0.001\end{array}$ & $\begin{array}{c}-0.36 \\
p<0.001\end{array}$ & $\begin{array}{c}1 \\
p<0.001\end{array}$ & & & & & & & \\
\hline Stress & $\begin{aligned} & 0.34 \\
p & <0.001\end{aligned}$ & $\begin{aligned} & -0.34 \\
p & <0.001\end{aligned}$ & $\begin{array}{c}-0.02 \\
p=0.621\end{array}$ & $\begin{array}{c}1 \\
p<0.001\end{array}$ & & & & & & \\
\hline Fatigue & $\begin{array}{c}0.11 \\
p=0.007\end{array}$ & $\begin{array}{l}-0.10 \\
p=0.017\end{array}$ & $\begin{array}{c}-0.02 \\
p=0.606\end{array}$ & $\begin{array}{c}0.31 \\
p<0.001\end{array}$ & $\begin{array}{c}1 \\
p<0.001\end{array}$ & & & & & \\
\hline Pain & $\begin{array}{c}0.02 \\
p=0.620\end{array}$ & $\begin{array}{c}-0.06 \\
p=0.180\end{array}$ & $\begin{array}{c}0.04 \\
p=0.327\end{array}$ & $\begin{array}{c}0.22 \\
p<0.001\end{array}$ & $\begin{array}{c}0.37 \\
p<0.001\end{array}$ & $\begin{array}{c}1 \\
p<0.001\end{array}$ & & & & \\
\hline $\begin{array}{l}\text { Positive } \\
\text { Affect }\end{array}$ & $\begin{array}{c}-0.15 \\
p<0.001\end{array}$ & $\begin{array}{c}0.14 \\
p=0.001\end{array}$ & $\begin{array}{c}0.02 \\
p=0.683\end{array}$ & $\begin{array}{c}-0.42 \\
p<0.001\end{array}$ & $\begin{array}{c}-0.28 \\
p<0.001\end{array}$ & $\begin{array}{c}-0.15 \\
p<0.001\end{array}$ & $\begin{array}{c}1 \\
p<0.001\end{array}$ & & & \\
\hline $\begin{array}{l}\text { Negative } \\
\text { Affect }\end{array}$ & $\begin{array}{c}\quad 0.21 \\
p<0.001\end{array}$ & $\begin{aligned} & -0.22 \\
p & <0.001\end{aligned}$ & $\begin{array}{c}-0.01 \\
p=0.829\end{array}$ & $\begin{aligned} & 0.72 \\
p & <0.001\end{aligned}$ & $\begin{array}{c}0.29 \\
p<0.001\end{array}$ & $\begin{aligned} & 0.23 \\
p & <0.001\end{aligned}$ & $\begin{array}{l}-0.54 \\
p<0.001\end{array}$ & $\begin{array}{c}1, \\
p<0.001\end{array}$ & & \\
\hline Task Load & $\begin{array}{c}0.41 \\
p<0.001\end{array}$ & $\begin{array}{c}-0.36 \\
p<0.001\end{array}$ & $\begin{array}{c}-0.08 \\
p=0.069\end{array}$ & $\begin{array}{c}0.43 \\
p<0.001\end{array}$ & $\begin{array}{c}0.23 \\
p<0.001\end{array}$ & $\begin{array}{c}0.11 \\
p=0.007\end{array}$ & $\begin{array}{c}-0.13 \\
p=0.002\end{array}$ & $\begin{array}{c}0.33 \\
p<0.001\end{array}$ & $\begin{array}{l}1 \\
p<0.001\end{array}$ & \\
\hline Work Hours & $\begin{array}{c}0.28 \\
p<0.001\end{array}$ & $\begin{array}{c}-0.14 \\
p=0.007\end{array}$ & $\begin{array}{c}-0.17 \\
p=0.001\end{array}$ & $\begin{array}{c}0.22 \\
p<0.001\end{array}$ & $\begin{array}{c}0.16 \\
p=0.001\end{array}$ & $\begin{array}{c}0.08 \\
p=0.109\end{array}$ & $\begin{array}{c}-0.12 \\
p=0.015\end{array}$ & $\begin{array}{c}0.12 \\
p=0.014\end{array}$ & $\begin{array}{c}0.31 \\
p<0.001\end{array}$ & $\begin{array}{c}1 \\
p<0.001\end{array}$ \\
\hline
\end{tabular}




\section{References}

1. Tamers, S.L.; Streit, J.; Pana-Cryan, R.; Ray, T.; Syron, L.; Flynn, M.A.; Castillo, D.; Roth, G.; Geraci, C.; Guerin, R.; et al. Envisioning the future of work to safeguard the safety, health, and well-being of the workforce: A perspective from the CDC's National Institute for Occupational Safety and Health. Am. J. Ind. Med. 2020, 63, 1065-1084. [CrossRef]

2. Eurofound; International Labour Office. Working Anytime, Anywhere: The Effects on the World of Work; Publications Office of the European Union: Luxembourg; International Labour Office: Geneva, Switzerland, 2017.

3. Gabriel, M.; Pessl, E. Industry 4.0 and sustainability impacts: Critical discussion of sustainability aspects with a special focus on future of work and ecological consequences. Ann. Fac. Eng. Hunedoara 2016, 14, 131.

4. Brynjolfsson, E.; Horton, J.; Ozimek, A.; Rock, D.; Sharma, G.; TuYe, H.-Y. COVID-19 and Remote Work: An Early Look at US Data; Report No.: w27344; National Bureau of Economic Research: Cambridge, MA, USA, 2020; p. w27344. Available online: http:/ / www.nber.org/papers/w27344.pdf (accessed on 17 August 2021).

5. Fukumura, Y.E.; Schott, J.M.; Lucas, G.M.; Becerik-Gerber, B.; Roll, S.C. Negotiating Time and Space When Working from Home: Experiences During COVID-19. OTJR Occup. Particip. Health 2021, 41, 223-231. [CrossRef]

6. Tamers, S.; Chosewood, L.; Childress, A.; Hudson, H.; Nigam, J.; Chang, C.-C. Total Worker Health ${ }^{\circledR} 2014-2018:$ The Novel Approach to Worker Safety, Health, and Well-Being Evolves. Int. J. Environ. Res. Public Health 2019, 16, 321. [CrossRef]

7. Chari, R.; Chang, C.-C.; Sauter, S.L.; Sayers, E.L.P.; Cerully, J.L.; Schulte, P.; Schill, A.L.; Uscher-Pines, L. Expanding the Paradigm of Occupational Safety and Health a New Framework for Worker Well-Being. J. Occup. Environ. Med. 2018, 60, 589-593. [CrossRef] [PubMed]

8. Sauter, S.L. Integrative Approaches to Safeguarding the Health and Safety of Workers. Ind. Health 2013, 51, 559-561. [CrossRef]

9. Meijman, T.F.; Mulder, G. Psychological aspects of workload. In Handbook of Work and Organizational: Work Psychology, 2nd ed.; Psychology Press: Hove, UK, 1998; Volume 2, pp. 5-33.

10. Sonnentag, S.; Fritz, C. The Recovery Experience Questionnaire: Development and validation of a measure for assessing recuperation and unwinding from work. J. Occup. Health Psychol. 2007, 12, 204-221. [CrossRef] [PubMed]

11. Pettican, A.; Prior, S. 'It's a New Way of Life': An Exploration of the Occupational Transition of Retirement. Br. J. Occup. Ther. 2011, 74, 12-19. [CrossRef]

12. Hart, S.G. NASA-task load index (NASA-TLX) 20 years later. In In Proceedings of the Human Factors and Ergonomics Society Annual Meeting; Sage publications: Los Angeles, CA, USA, 2006; pp. 904-908.

13. Dich, N.; Lange, T.; Head, J.; Rod, N.H. Work Stress, Caregiving and Allostatic Load: Prospective results from Whitehall II cohort study. Psychosom. Med. 2015, 77, 539-547. [CrossRef] [PubMed]

14. Demerouti, E.; Bakker, A.B.; Geurts, S.A.E.; Taris, T.W. Daily Recovery from Work-Related Effort During Non-Work Time. Res. Occup. Stress Well Being 2009, 7, 85-123.

15. Bowling, N.A.; Alarcon, G.M.; Bragg, C.B.; Hartman, M.J. A meta-analytic examination of the potential correlates and consequences of workload. Work Stress 2015, 29, 95-113. [CrossRef]

16. Radic, A.; Arjona-Fuentes, J.M.; Ariza-Montes, A.; Han, H.; Law, R. Job demands-Job resources (JD-R) model, work engagement, and well-being of cruise ship employees. Int. J. Hosp. Manag. 2020, 88, 102518. [CrossRef]

17. Ariza-Montes, A.; Hernández-Perlines, F.; Han, H.; Law, R. Human dimension of the hospitality industry: Working conditions and psychological well-being among European servers. J. Hosp. Tour. Manag. 2019, 41, 138-147. [CrossRef]

18. Bennett, A.A.; Bakker, A.B.; Field, J.G. Recovery from work-related effort: A meta-analysis. J. Organ. Behav. 2018, 39, $262-275$. [CrossRef]

19. Sonnentag, S. Work, recovery activities, and individual well-being: A diary study. J. Occup. Health Psychol. 2001, 6, 196. [CrossRef] [PubMed]

20. Bakker, A.B.; Demerouti, E. The Job Demands-Resources model: State of the art. J. Manag. Psychol. 2007, 22, 309-328. [CrossRef]

21. Shiffman, S.; Stone, A.A.; Hufford, M.R. Ecological momentary assessment. Annu. Rev. Clin. Psychol. 2008, 4, 1-32. [CrossRef] [PubMed]

22. Pressman, S.D.; Matthews, K.A.; Cohen, S.; Martire, L.M.; Scheier, M.; Baum, A.; Schulz, R. Association of Enjoyable Leisure Activities with Psychological and Physical Well-Being. Psychosom. Med. 2009, 71, 725-732. [CrossRef]

23. Dababneh, A.J.; Swanson, N.; Shell, R.L. Impact of added rest breaks on the productivity and well being of workers. Ergonomics 2001, 44, 164-174. [CrossRef]

24. Pyatak, E.A.; Hernandez, R.; Pham, L.; Mehdiyeva, K.; Schneider, S.; Peters, A.; Ruelas, V.; Crandall, J.; Lee, P.-J.; Jin, H.; et al. Function and Emotion in Everyday Life with Type 1 Diabetes (FEEL-T1D): A fully remote intensive longitudinal study of blood glucose, function, and emotional well-being in adults with type 1 diabetes (Preprint). JMIR Res. Protoc. 2021. Available online: http:/ / preprints.jmir.org/preprint/30901 (accessed on 10 September 2021).

25. Harris, P.A.; Taylor, R.; Thielke, R.; Payne, J.; Gonzalez, N.; Conde, J.G. Research electronic data capture (REDCap)—A metadatadriven methodology and workflow process for providing translational research informatics support. J. Biomed. Inform. 2009, 42, 377-381. [CrossRef]

26. Laurenceau, J.-P. Using Mobile Devices to Study Daily Diabetes Management in Marital; Context NIDDK/NIH (R21DK098679); University of Delaware: Newark, DE, USA, 2013.

27. American Occupational Therapy Association. Occupational Therapy Practice Framework: Domain and Process-Fourth Edition. Am. J. Occup Ther. 2020, 74, 7412410010. 
28. Tudor-Locke, C.; Washington, T.L.; Ainsworth, B.E.; Troiano, R.P. Linking the American Time Use Survey (ATUS) and the compendium of physical activities: Methods and rationale. J. Phys. Act. Health 2009, 6, 347-353. [CrossRef]

29. Legg, L.; Weir, C.J.; Langhorne, P.; Smith, L.N.; Stott, D.J. Is informal caregiving independently associated with poor health? A population-based study. J. Epidemiol. Community Health 2013, 67, 95-97. [CrossRef]

30. Murphy, N.A.; Christian, B.; Caplin, D.A.; Young, P.C. The health of caregivers for children with disabilities: Caregiver perspectives. Child Care Health Dev. 2007, 33, 180-187. [CrossRef]

31. Cohen, C.A.; Colantonio, A.; Vernich, L. Positive aspects of caregiving: Rounding out the caregiver experience. Int. J. Geriatr. Psychiatry 2002, 17, 184-188. [CrossRef]

32. Brown, S.L.; Smith, D.M.; Schulz, R.; Kabeto, M.U.; Ubel, P.A.; Poulin, M.; Yi, J.; Kim, C.; Langa, K.M. Caregiving Behavior Is Associated with Decreased Mortality Risk. Psychol. Sci. 2009, 20, 488-494. [CrossRef] [PubMed]

33. Buyck, J.-F.; Bonnaud, S.; Boumendil, A.; Andrieu, S.; Bonenfant, S.; Goldberg, M.; Zins, M.; Ankri, J. Informal Caregiving and Self-Reported Mental and Physical Health: Results from the Gazel Cohort Study. Am. J. Public Health 2011, 101, 1971-1979. [CrossRef] [PubMed]

34. Rose, M.S.; Noelker, L.S.; Kagan, J. Improving Policies for Caregiver Respite Services. Gerontologist 2015, 55, 302-308. [CrossRef] [PubMed]

35. Tindle, J.; Tadi, P. Neuroanatomy, Parasympathetic Nervous System; StatPearls Publishing: Treasure Island, FL, USA, 2021. Available online: http:/ / www.ncbi.nlm.nih.gov/books/NBK553141/ (accessed on 24 June 2021).

36. Stebbins, R.A. Casual leisure: A conceptual statement. Leis. Stud. 1997, 16, 17-25. [CrossRef]

37. Zimmerman, M.E. Task Load. In Encyclopedia of Clinical Neuropsychology; Kreutzer, J.S., DeLuca, J., Caplan, B., Eds.; Springer: New York, NY, USA, 2011; pp. 2469-2470. [CrossRef]

38. Hart, S.G.; Staveland, L.E. Development of NASA-TLX (Task Load Index): Results of Empirical and Theoretical Research. In Advances in Psychology; Elsevier: Amsterdam, The Netherlands, 1988; pp. 139-183. Available online: https:/ /linkinghub.elsevier. com/retrieve/pii/S0166411508623869 (accessed on 24 March 2019).

39. Hoonakker, P.; Carayon, P.; Gurses, A.; Brown, R.; McGuire, K.; Khunlertkit, A.; Walker, J.M. Measuring Workload of ICU Nurses with a Questionnaire Survey: The NASA Task Load Index (TLX). IIE Trans. Healthc. Syst. Eng. 2011, 1, 131-143. [CrossRef]

40. Chari, R.; Chang, C.-C.; Sauter, S.L.; Sayers, E.L.P.; Huang, W.; Fisher, G.G. NIOSH Worker Well-Being Questionnaire (WellBQ); CDC: Atlanta, GA, USA, 2021.

41. Scott, S.B.; Sliwinski, M.J.; Zawadzki, M.; Stawski, R.S.; Kim, J.; Marcusson-Clavertz, D.; Lanza, S.T.; Conroy, D.E.; Buxton, O.; Almeida, D.M.; et al. A Coordinated Analysis of Variance in Affect in Daily Life. Assessment 2020, 27, 1683-1698. [CrossRef]

42. Crawford, J.R.; Henry, J.D. The Positive and Negative Affect Schedule (PANAS): Construct validity, measurement properties and normative data in a large non-clinical sample. Br. J. Clin. Psychol. 2004, 43, 245-265. [CrossRef]

43. Broderick, J.E.; Schwartz, J.E.; Schneider, S.; Stone, A.A. Can end-of-day reports replace momentary assessment of pain and fatigue? J. Pain 2009, 10, 274-281. [CrossRef]

44. Mendoza, T.R.; Wang, X.S.; Cleeland, C.S.; Morrissey, M.; Johnson, B.A.; Wendt, J.K.; Huber, S.L. The rapid assessment of fatigue severity in cancer patients: Use of the Brief Fatigue Inventory. Cancer 1999, 85, 1186-1196. [CrossRef]

45. Daut, R.L.; Cleeland, C.S. The prevalence and severity of pain in cancer. Cancer 1982, 50, 1913-1918. [CrossRef]

46. Dunton, G.F.; Ke, W.; Dzubur, E.; O'Connor, S.G.; Lopez, N.V.; Margolin, G. Within-Subject Effects of Stress on Weight-Related Parenting Practices in Mothers: An Ecological Momentary Assessment Study. Ann. Behav. Med. 2018, 53, 415-425. [CrossRef] [PubMed]

47. Sonnenberg, B.; Riediger, M.; Wrzus, C.; Wagner, G.G. Measuring Time Use in Surveys—How Valid are Time Use Questions in Surveys? Concordance of Survey and Experience Sampling Measures. SSRN J. 2012, 41, 1037-1052. Available online: http:/ / www.ssrn.com/abstract=1895307 (accessed on 19 December 2020). [CrossRef]

48. Bates, D.; Mächler, M.; Bolker, B.; Walker, S. Fitting Linear Mixed-Effects Models Using lme4. J. Stat. Softw. 2015, 67, 1-48. [CrossRef]

49. Bell, B. 433-2013: A Multilevel Model Primer Using SAS ${ }^{\circledR}$ PROC MIXED; SAS Institute: Cary, NC, USA, 2013 ; p. 19.

50. Luke, S.G. Evaluating significance in linear mixed-effects models in R. Behav. Res. 2017, 49, 1494-1502. [CrossRef] [PubMed]

51. Appiah, A.K. Bootstrap Linear Mixed-Effects Models Using SAS ${ }^{\circledR}$ Procedures; SAS Institute: Cary, NC, USA, $2018 ;$ p. 17.

52. Bakdash, J.Z.; Marusich, L.R. Repeated Measures Correlation. Front. Psychol. 2017, 8, 456. [CrossRef]

53. Merz, E.L.; Roesch, S.C. Modeling trait and state variation using multilevel factor analysis with PANAS daily diary data. J. Res. Pers. 2011, 45, 2-9. [CrossRef]

54. Roesch, S.C.; Aldridge, A.A.; Stocking, S.N.; Villodas, F.; Leung, Q.; Bartley, C.E.; Black, L.J. Multilevel Factor Analysis and Structural Equation Modeling of Daily Diary Coping Data: Modeling Trait and State Variation. Multivar. Behav. Res. 2010, 45, 767-789. [CrossRef]

55. Cohen, J. Statistical Power Analysis for the Behavioral Sciences; Academic Press: Cambridge, MA, USA, 2013.

56. Rook, J.W.; Zijlstra, F.R.H. The contribution of various types of activities to recovery. Eur. J. Work Organ. Psychol. 2006, 15, 218-240. [CrossRef]

57. Abma, I.L.; Rovers, M.; van der Wees, P.J. Appraising convergent validity of patient-reported outcome measures in systematic reviews: Constructing hypotheses and interpreting outcomes. BMC Res Notes 2016, 9, 226. Available online: https: / / www.ncbi. nlm.nih.gov/pmc/articles/PMC4837507/ (accessed on 22 March 2021). [CrossRef] 
58. Terwee, C.B.; Bot, S.D.M.; de Boer, M.R.; van der Windt, D.A.W.M.; Knol, D.L.; Dekker, J.; Bouter, L.M.; de Vet, H.C.W. Quality criteria were proposed for measurement properties of health status questionnaires. J. Clin. Epidemiol. 2007, 60, 34-42. [CrossRef] [PubMed]

59. Engelen, L.; Chau, J.Y.; Burks-Young, S.; Bauman, A. Application of ecological momentary assessment in workplace health evaluation. Health Promot. J. Aust. 2016, 27, 259-263. [CrossRef] [PubMed]

60. Lorig, K.R.; Sobel, D.S.; Stewart, A.L.; Brown, B.W.; Bandura, A.; Ritter, P.; Gonzalez, V.M.; Laurent, D.D.; Holman, H.R. Evidence Suggesting That a Chronic Disease Self-Management Program Can Improve Health Status While Reducing Hospitalization: A Randomized Trial. Med. Care 1999, 37, 5-14. [CrossRef]

61. Dixon, A.; Hibbard, J.; Tusler, M. How do People with Different Levels of Activation Self-Manage their Chronic Conditions? Patient Patient-Cent. Outcome Res. 2009, 2, 257-268. [CrossRef] [PubMed]

62. Devins, G.M. Using the Illness Intrusiveness Ratings Scale to understand health-related quality of life in chronic disease. J. Psychosom. Res. 2010, 68, 591-602. [CrossRef]

63. Keles, H.; Ekici, A.; Ekici, M.; Bulcun, E.; Altinkaya, V. Effect of chronic diseases and associated psychological distress on health-related quality of life. Intern. Med. J. 2007, 37, 6-11. [CrossRef]

64. Schokker, M.C.; Links, T.P.; Luttik, M.L.; Hagedoorn, M. The association between regulatory focus and distress in patients with a chronic disease: The moderating role of partner support. Br. J. Health Psychol. 2010, 15, 63-78. [CrossRef]

65. Raghupathi, W.; Raghupathi, V. An Empirical Study of Chronic Diseases in the United States: A Visual Analytics Approach to Public Health. Int. J. Environ. Res. Public Health 2018, 15, 431. Available online: https:/ /www.ncbi.nlm.nih.gov/pmc/articles/ PMC5876976/ (accessed on 23 March 2021).

66. Xu, G.; Liu, B.; Sun, Y.; Du, Y.; Snetselaar, L.G.; Hu, F.B.; Bao, W. Prevalence of diagnosed type 1 and type 2 diabetes among US adults in 2016 and 2017: Population-based study. BMJ 2018, 362, k1497. [CrossRef]

67. Davies, M.J.; Gagliardino, J.J.; Gray, L.J.; Khunti, K.; Mohan, V.; Hughes, R. Real-world factors affecting adherence to insulin therapy in patients with Type 1 or Type 2 diabetes mellitus: A systematic review. Diabet. Med. 2013, 30, 512-524. [CrossRef] [PubMed]

68. Coccaro, E.F.; Lazarus, S.; Joseph, J.; Wyne, K.; Drossos, T.; Phillipson, L.; de Groot, M. Emotional Regulation and Diabetes Distress in Adults with Type 1 and Type 2 Diabetes. Diabetes Care 2021, 44, 20-25. [CrossRef] [PubMed]

69. Trull, T.J.; Ebner-Priemer, U.W. Ambulatory Assessment in Psychopathology Research: A Review of Recommended Reporting Guidelines and Current Practices. J. Abnorm. Psychol. 2020, 129, 56-63. [CrossRef] [PubMed]

70. Cranford, J.A.; Shrout, P.E.; Iida, M.; Rafaeli, E.; Yip, T.; Bolger, N. A Procedure for Evaluating Sensitivity to Within-Person Change: Can Mood Measures in Diary Studies Detect Change Reliably? Pers. Soc. Psychol Bull. 2006, 32, 917-929. [CrossRef]

71. Reichenberger, J.; Pannicke, B.; Arend, A.-K.; Petrowski, K.; Blechert, J. Does stress eat away at you or make you eat? EMA measures of stress predict day to day food craving and perceived food intake as a function of trait stress-eating. Psychol. Health 2021, 36, 129-147. [CrossRef]

72. Fisher, G.G.; Matthews, R.A.; Gibbons, A.M. Developing and investigating the use of single-item measures in organizational research. J. Occup. Health Psychol. 2016, 21, 3-23. [CrossRef]

73. Cursio, J.F.; Mermelstein, R.J.; Hedeker, D. Latent trait shared-parameter mixed models for missing ecological momentary assessment data. Stat. Med. 2019, 38, 660-673. [CrossRef] 